\title{
GALERI SENI DAUR ULANG SAMPAH DI JAKARTA
}

\author{
Selly ${ }^{1)}$, Diah Anggraini ${ }^{2)}$ \\ ${ }^{1)}$ Program Studi S1 Arsitektur, Fakultas Teknik, Universitas Tarumanagara, sellylim1122@gmail.com \\ 2) Program Studi S1 Arsitektur, Fakultas Teknik, Universitas Tarumanagara, diah_ismono@yahoo.com
}

\begin{abstract}
Abstrak
Jakarta merupakan kota metropolitan yang padat dan mempunyai beraneka macam kegiatan yang seharusnya memiliki pendaur ulangan sampah yang baik dan masyarakatnya sadar tentang daur ulang sampah. Aspek ini merupakan salah satu hal yang dianggap penting karena memengaruhi kualitas hidup masyarakat dan lingkungannya. Seharusnya sampah dapat lebih dimanfaatkan kembali atau dijadikan produk baru yang memiliki nilai guna dan nilai ekonomis. Perspektif tentang sampah yang negatif dapat berubah dengan tambahan aspek kreatifitas yang dapat menciptakan berbagai jenis produk dengan nilai jual dan nilai seni. Kawasan Sunda Kelapa sebagai salah satu tempat wisata bahari yang terkenal namun kurang terawat, salah satu penyebabnya adalah sampah yang berserakan menumpuk. Tindakan diwujudkan dengan mengusulkan sebuah wadah pendaur ulangan sampah dalam bentuk galeri untuk pameran benda-benda seni terbuat dari sampah dan bengkel kerja kerajinan tangan dari sampah terutama kertas, plastik, kaca dan metal. Pameran ini sebagai salah satu cara untuk menyentuh masyarakat tentang edukasi persampahan dan menjadi tempat wisata baru yang berhubungan dengan tempat wisata lain disekitarnya sekaligus memecahkan permasalahan sampah di lingkungan dan workshop yang menciptakan barangbarang kreatif dan keunikan yang dapat menarik para pengunjung. Lokasi tapak berada di antara Museum Bahari dan Pelabuhan Sunda Kelapa membentuk linkage dengan kawasan Kota Tua yang menjadikan potensi tapak sebagai objek wisata. Dengan adanya linkage dengan bangunan-bangunan kota tua, hal ini dapat dijadikan dasar metode desain yang akan diterapkan dalam pembentukkan massa dan penggunaan material. Dengan memanfaatkan linkage akan menciptakan bangunan yang selaras dengan bangunan sekitar.
\end{abstract}

Kata kunci: daur ulang, galeri, sampah, seni.

\begin{abstract}
Jakarta is a metropolitan city that is dense and has a wide range of activities that should have a good recycling of waste and public awareness about waste recycling. This aspect is one of the things that is considered important because it affects the quality of life of the community and its environment. Garbage should be used more or become a new product that has use value and economic value. Negative perspectives on waste can change with additional aspects of creativity that can create various types of products with selling value and artistic value. Sunda Kelapa area as one of the famous maritime tourist spots but not well maintained, one of the reasons is the scattered garbage piled up. The action was realized by proposing a recycle bin in the form of a gallery to exhibit art objects made of garbage and handicraft workshops from garbage, especially paper, plastic, glass and metal. This exhibition is one way to touch the public about solid waste education and become a new tourist place that is related to other tourist attractions around it as well as solving waste problems in the environment and workshops that create creative and unique items that can attract visitors. The location of the site is between the Maritime Museum and Sunda Kelapa Harbor forming a linkage with the Kota Tua area which makes the potential of the site a tourist attraction. With the existence of linkage with old city buildings, this can be used as the basis of the design method that will be applied in the formation of mass and material use. Using linkage will create buildings that are in harmony with the surrounding buildings.
\end{abstract}

Keywords: art, gallery, recycling, waste. 


\section{PENDAHULUAN}

Jakarta merupakan salah satu kota metropolitan di Indonesia yang banyak kegiatan terjadi seperti perekonomian, perdagangan, hiburan, dan lain-lain. Berbagai macam kegiatan yang telah disebutkan diatas menjadi salah satu faktor yang dapat memberikan keuntungan bagi segi perekonomian, tetapi menimbulkan efek negatif yaitu berupa sisa hasil yang berupa sampah. Pemilahan sampah sesuai jenisnya tidak sehingga sulit untuk didaur ulang.

Kawasan Sunda Kelapa adalah salah satu daerah di Jakarta Utara yang merupakan objek pariwisata yang populer, namun terdapat sampah yang bertaburan yang menumpuk dan merusak pemandangan sehingga mempengaruhi aspek wisata di kawasan. Hal ini menjadi penting dan menarik sebagai suatu potensi yang terdapat di daerah Sunda Kelapa. Potensi yang terdapat di daerah ini adalah lokasi telah menjadi objek wisata, namun memiliki kendala lain dari tumpukan sampah yang ada. Sampah yang biasa dianggap sebagai hal negatif disini, tetapi bisa juga dianggap sebagai nilai tambah dalam menciptakan suatu karya yang berasal dari sampah daerah sekitar. Sampah yang dipakai didominasi sampah rumah tangga berupa kaca, metal, plastik, dan kertas karena merupakan penghasil sampah terbesar. Dengan ini kita dapat menciptakan suatu potensi lewat wadah kreatifitas mengenai sisa hasil sampah yang bisa dibuat daur ulang menjadi sebuah produk yang memiliki nilai jual, selain itu bisa juga menggiatkan sumber daya masyarakat sekitar untuk mendorong wadah ini menjadi menarik dan berguna bagi pengembangan pariwisata lewat produksi hasil daur sampah berupa suatu kerajinan, maupun suatu karya seni.

Proyek yang diusulkan adalah sebuah galeri yang berfungsi sebagai tempat pameran bendabenda seni dengan bahan dasar sampah hasil dari seniman-seniman lokal sebagai sikap yang menunjukkan kepedulian terhadap lingkungan dan workshop sebagai bengkel kerja penghasil kerajinan tangan dari sampah (plastik, kertas, metal dan kaca) yang akan diperjual belikan sebagai oleh-oleh. Workshop akan memanfaatkan masyarakat sekitar sehingga dapat meningkatkan perekonomian dan meningkatkan kesadaran mereka. Sampah yang digunakan didapatkan dari sekitar kawasan yang akan dilakukan proses pemilahan, pengolahan hingga siap menjadi bahan baku siap pakai. Penerapan edukasi dilakukan melalui penjelasan lengkap mengenai sampah dan lingkungan untuk memberikan pengetahuan dan membuka pikiran wisatawan.

Lokasi tapak berada di Jalan Lodan Raya yang strategis karena terletak di kawasan perencanaan wisata bahari dengan menjadikannya sebagai linkage. Tapak dan objek wisata di kawasan akan menjadi satu linkage bersama dengan kawasan Kota Tua sehingga tapak memiliki potensi wisata yang tinggi. Penggunaan strategi ini akan ditunjukan dalam pembentukkan gubahan massa yang mengikuti ciri bangunan Kota Tua. Pengembangan program ini selaras dengan program pemerintah mengenai kreatifitas daur ulang sampah berbasis entrepreneurship dan juga dapat serta menggerakan potensi pariwisata dalam isu kelingkungan di kawasan sekitar Sunda Kelapa.

Diharapkan melalui proyek ini akan meningkatkan pariwisata kota Jakarta terutama kawasan Sunda Kelapa karena sampah digabungkan dengan seni adalah hal yang unik dan patut untuk diketahui dan dapat mengurangi permasalahan sampah di kawasan. Desain proyek memiliki kualitas sebagai suatu bangunan architourism yang dapat menjadi daya tarik.

\section{KAJIAN LITERATUR}

Linkage adalah garis semu yang menghubungkan satu elemen dengan elemen lainnya, nodes dengan nodes lainnya, atau distrik dengan distrik lainnya. Garis ini bisa berupa jaringan jalan, jalur pedestrian, ruang terbuka, dan lain-lain. Teori linkage melibatkan pengorganisasian garis penghubung yang menghubungkan bagian-bagian kota dan design "special datum" dari garis bangunan kepada ruang. Spacial datum dapat berupa site line, arah pergerakan, aksis maupun tepian bangunan. Dalam teori, linkage memperhatikan susunan dari hubungan bagian kota satu dengan kota lainnya. Sirkulasi merupakan penekanan dari teori linkage yang 
mempertegas hubungan-hubungan dan dinamika dari urban fabric.

Teori linkage merupakan bentukan kota tidak lepas dari adanya jaring-jaring sirkulasi (network circulation). Network yang ada dapat berupa jalan, jalur pedestrian, ruang terbuka yangberbentuk linier ataupun bentuk-bentuk yang secara fisik menjadi penghubung antar bagian kota/kawasan.

\section{METODE}

Metode pendekatan dengan sudut pandang kota ini hadir dalam bentuk perwujudan arsitektural dengan konsep linkage yang menghubungkan bangunan kota tua dengan bangunan baru. Tindakan ini bertujuan untuk mewujudkan arsitektur yang selaras dengan lingkungan sekitar.

Konsep dasar desain menggunakan analisis dari bangunan-bangunan di Kota Tua yang memiliki ciri khas yang selalu ada di setiap bangunannya. Bentuk bangunan, pengunaan inner court yard, main entrance, pengunaan material berdasarkan konsep identitas bangunan di Kota Tua. Penerapan ini diharapkan dapat menciptakan bangunan yang selaras namun modern. Aksesibilitas merupakan salah satu kekuataan dari kawasan karena menurut Rencana Detail Tata Ruang tahun 2030 akan diciptakan tambahan pemberhentian moda transportasi yang memudahkan pengunjung untuk segi pencapaian dan perpindahan.

\section{DISKUSI DAN HASIL}

\section{Pengenalan Kawasan}

Analisis pertimbangan kawasan diawali dengan peninjauan Jakarta. Sebagai kota metropolitan, Jakarta telah tumbuh begitu pesat sehingga mengharuskan perubahan unutuk mengikuti perkembangan dan kebutuhan zaman. Selanjutnya, dilakukan analisis aspek strategis, hal ini dilakukan untuk menganalisis kawasan dari beberapa aspek terkait yang relevan.

Survey pada daerah kawasan Sunda Kelapa dan wawancara kepada masyarakat sekitar seperti penduduk, pedagang kaki lima, serta wisatawan yang berkunjung. Hal yang ditanyakan seputar kebersihan, perilaku masyarakat dalam membuang sampah, ilmu masyarakat tentang pemilahan dan pengelolaan. Hasilnya $92 \%$ tidak pernah memilah sampahnya sebelum dibuang, $6 \%$ kadang-kadang memilah sampah, dan hanya $2 \%$ yang selalu memilah sampahnya. Pertanyaan seperti ini diajukan untuk mengetahui reaksi dan pendapat masyarakat mengenai sampah.

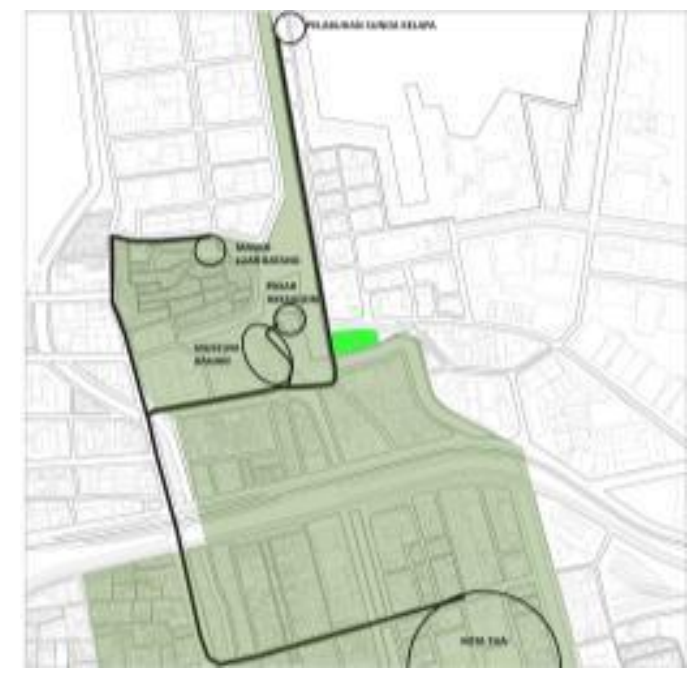

Gambar 1. Lingkage Kawasan Sekitar Sumber: Olahan penulis, 2018 


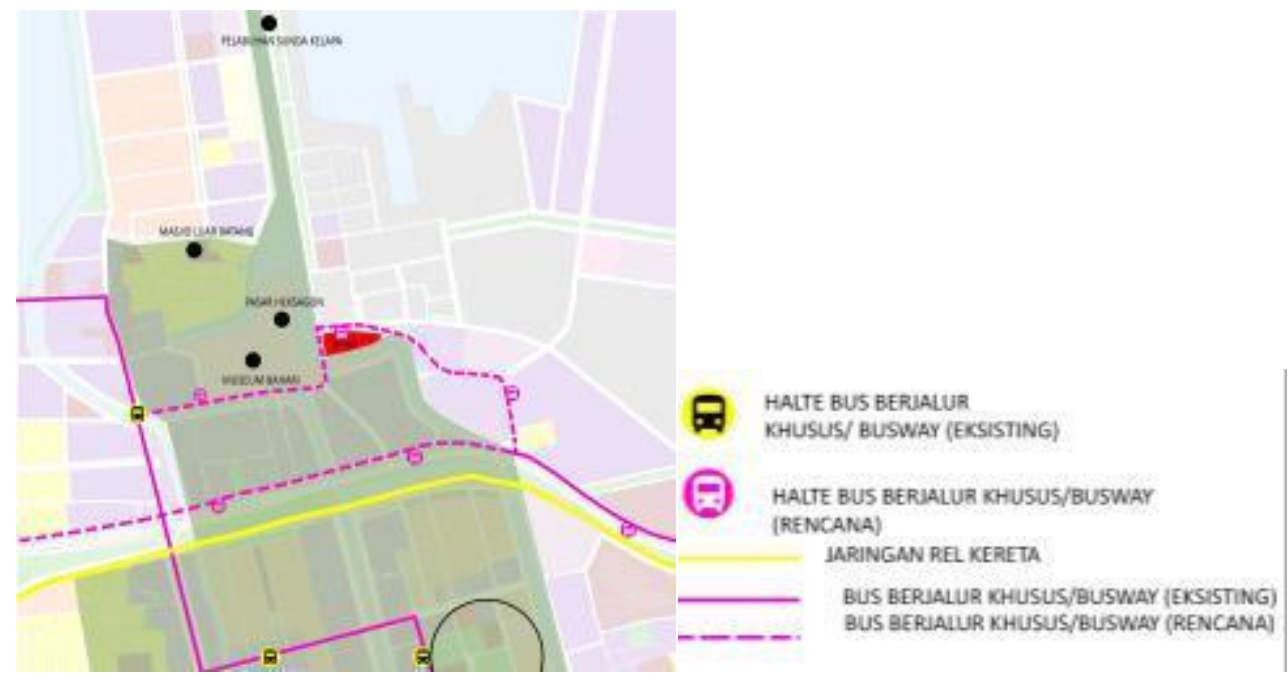

Gambar 2. Linkage Titik Transportasi yang Berhubungan Sumber: Olahan penulis, 2018.

Gambar 3. Prosentase Rumah Tangga yang Memilah Sampah Sumber: Olahan penulis, 2018.

Dari kegiatan tersebut telah diketahui kondisi Jakarta yang sekarang telah menunjukkan krisis sampah dimana perkembangan kota tidak diimbangi dengan kemajuan fasilitas sampah dan kesadaran masyarakat yang masih sangat rendah. Kawasan Sunda Kelapa adalah kawasan yang memerlukan tindakan penyembuhan dari darurat sampah dalam rangka meningkatkan kenyamanan dan kualitas lingkungan Jakarta.

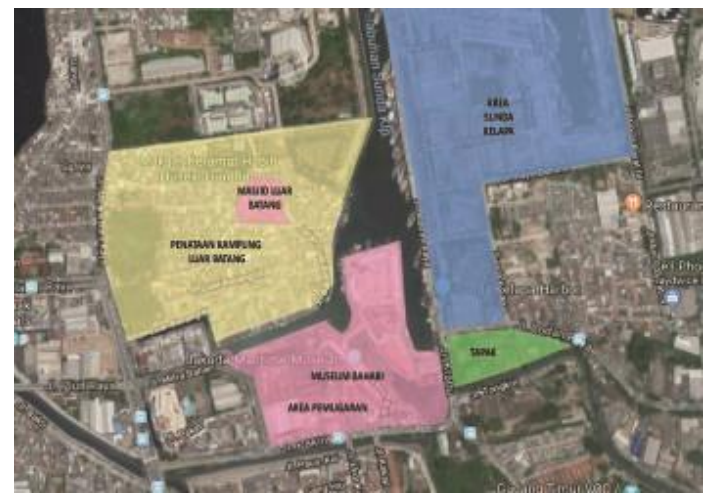

Gambar 4. Perencanaan Pengembangan Wisata Bahari Sumber: Olahan penulis, 2018. 
Pemerintah Provinsi DKI Jakarta berencana menertibkan pemukiman warga di atas tanggul, badan air laut, dan saluran kali di kawasan Luar Batang dalam rangka revitalisasi kawasan wisata Sunda Kelapa, Museum Bahari dan Kawasan Luar Batang.

\section{Analisis Pelaku Kegiatan}

Tabel 1. Analisis Pelaku Kegiatan

\begin{tabular}{|c|c|c|c|}
\hline $\begin{array}{l}\text { Kategori } \\
\text { Pelaku }\end{array}$ & $\begin{array}{c}\text { Pelaku } \\
\text { Kegiatan }\end{array}$ & Keterangan & Kegiatan \\
\hline \multirow[t]{3}{*}{ Pengunjung } & $\begin{array}{l}\text { Wisatawan } \\
\text { lokal }\end{array}$ & $\begin{array}{l}\text { Wisatawan dalam kota, berkunjung untuk } \\
\text { menikmati seni dan bisa berupa study } \\
\text { tour. }\end{array}$ & \multirow{3}{*}{$\begin{array}{l}\text { Menikmati karya } \\
\text { Makan } \\
\text { Berfoto } \\
\text { Belajar } \\
\text { Beli tiket } \\
\text { Belanja } \\
\text { Toilet } \\
\end{array}$} \\
\hline & $\begin{array}{l}\text { Wisatawan } \\
\text { luar kota }\end{array}$ & $\begin{array}{l}\text { Wisatawan dari luar Jakarta, berkunjung } \\
\text { untuk belajar dan wisata. }\end{array}$ & \\
\hline & $\begin{array}{l}\text { Wisatawan } \\
\text { luar negeri }\end{array}$ & $\begin{array}{l}\text { Wisatawan asing, datang karena rasa ingin } \\
\text { tahu dan keinginan mengenal hal baru. }\end{array}$ & \\
\hline \multirow[t]{5}{*}{ Pengelola } & $\begin{array}{l}\text { Pengelola } \\
\text { Gedung }\end{array}$ & $\begin{array}{l}\text { Mengatur pemasaran dan managemen } \\
\text { pemakaian gedung. }\end{array}$ & \multirow{5}{*}{$\begin{array}{l}\text { Ticketing } \\
\text { Dokumentasi } \\
\text { Penataan } \\
\text { Toilet } \\
\text { Pemasaran } \\
\text { Pengaturan Sampah }\end{array}$} \\
\hline & $\begin{array}{l}\text { Pengelola } \\
\text { Umum }\end{array}$ & $\begin{array}{l}\text { Mengatur kebersihan dan perawatan } \\
\text { gedung. }\end{array}$ & \\
\hline & $\begin{array}{l}\text { Pengelola } \\
\text { Galeri }\end{array}$ & Mengatur kegiatan galeri. & \\
\hline & $\begin{array}{l}\text { Pengelola } \\
\text { Workshop }\end{array}$ & Mengatur pekerja dan bahan mentah. & \\
\hline & $\begin{array}{l}\text { Pengelola } \\
\text { Sampah }\end{array}$ & $\begin{array}{l}\text { Mengatur pemilahan dan penerimaan } \\
\text { sampah. }\end{array}$ & \\
\hline \multirow[t]{2}{*}{ Pekerja } & Seniman & $\begin{array}{l}\text { Pencipta karya seni yang akan dipamerkan } \\
\text { di galeri. }\end{array}$ & \multirow{2}{*}{$\begin{array}{l}\text { Bekerja } \\
\text { Makan } \\
\text { Loker } \\
\text { Toilet }\end{array}$} \\
\hline & PKK & Pembuat produk yang akan dijual. & \\
\hline
\end{tabular}

Sumber: Olahan penulis, 2018

\section{Konsep Perancangan}

\section{Program Ruang}

Tabel 2. Program Ruang

\begin{tabular}{|c|c|c|c|}
\hline No. & Penunjang & Nama Ruangan & Luasan \\
\hline 1 & \multirow{5}{*}{ Utama } & Exhibition Room & $1.550 \mathrm{~m}^{2}$ \\
\hline 2 & & Workshop & $512 \mathrm{~m}^{2}$ \\
\hline 3 & & Knowledge Center & $130 \mathrm{~m}^{2}$ \\
\hline 4 & & Simulation Center & $141 \mathrm{~m}^{2}$ \\
\hline 5 & & Installation Art Room & $251 \mathrm{~m}^{2}$ \\
\hline 6 & \multirow{3}{*}{ Pendukung } & Restoran & $200 \mathrm{~m}^{2}$ \\
\hline 7 & & Retail & $261 \mathrm{~m}^{2}$ \\
\hline 8 & & Perkantoran & $690 \mathrm{~m}^{2}$ \\
\hline 9 & \multirow{2}{*}{ Servis } & Area Pengolahan Sampah & $460 \mathrm{~m}^{2}$ \\
\hline 10 & & Area Parkir & $2593 \mathrm{~m}^{2}$ \\
\hline
\end{tabular}

Sumber: Olahan penulis, 2018

\section{Tapak}

Tapak berada di Jalan Lodan Raya No. 1 RT1/RW. 8, Kota Tua, Ancol, Pademangan, Jakarta Utara, DKI Jakarta 14430 dengan luas tanah $8.000 \mathrm{~m} 2$ yang memiliki zona perkantoran dagang dan jasa. Maksimal ketinggian bangunan 4 (empat lantai). Tapak dengan void sebagai inner court yang berfungsi untuk sirkulasi udara dan cahaya alami dalam bangunan. Dinding luar bangunan mengikuti garis sempadan bangunan yang telah ditetapkan sebagai ciri khas 
bangunan kota tua. Entrance utama bangunan dibuat lebih menonjol sebagai point of interest. Bentuk bangunan yang kebanyakan memanjang dan pipih dengan tampak bangunan cenderung rata ke atas dan fasad yang berirama.

Tabel 3. Besaran Luas Proyek dan Data Tapak

\begin{tabular}{|c|c|c|}
\hline & Desain Program & Ketentuan \\
\hline KDB (Koefisien Dasar Bangunan) & $3.773 \mathrm{M}^{2}(48 \%)$ & $4.000 \mathrm{M}^{2}(50 \%)$ \\
\hline KTB (Koefisien Tapak Basement) & $4.332 \mathrm{M}(54 \%)$ & $4.400 \mathrm{M}^{2}(55 \%)$ \\
\hline KLB (Koefisien Luas Bangunan) & 1.5 & 2 \\
\hline KDH (Koefisien Dasar Hijau) & $2.530 \mathrm{M}^{2}(31 \%)$ & $2.400 \mathrm{M}^{2}(30 \%)$ \\
\hline Total Luas & \multicolumn{2}{|c|}{$12.935 \mathrm{M}^{2}$} \\
\hline
\end{tabular}

Sumber: Olahan penulis, 2018

\section{Gubahan Massa}

Tabel 4. Proses Pembentukan Gubahan Massa

\begin{tabular}{|c|c|}
\hline Gambar & Strategi Desain \\
\hline & $\begin{array}{l}\text { Gubahan massa awal mengikuti bentuk tapak dan garis sempadan } \\
\text { bangunan (GSB). }\end{array}$ \\
\hline & $\begin{array}{l}\text { Void di tengah massa sebagai ruang terbuka, pencahayaan dan } \\
\text { pengudaraan alami. }\end{array}$ \\
\hline & Pengunaan perbedaan tinggi untuk menghilangkan kesan massive. \\
\hline & Pengunaan ramping untuk menciptakan sirkulasi yang menerus. \\
\hline
\end{tabular}

Sumber : Olahan penulis, 2018

\section{Sirkulasi pada Tapak dan Bangunan}

Dengan menerapkan konsep linkage menjadikan sirkulasi sebagai penekanan dalam hal mendesign. Sirkulasi dengan maksud mempelajari sebuah pola pergerakan manusia dari suatu tempat ke tempat lain dan membentuk sebuah keterhubungan karakter bangunan. Terkait dengan kondisi Kawasan Sunda Kelapa saat ini, penting sekali sirkulasi yang menghubungkan beberapa titik wisata untuk mengembangkan seluruh kawasan dan meningkatkan perekonomian masyarakat sekitar dengan pemulihan lingkungan. Aksesibilitas direncanakan akan lebih baik kedepannya dengan pelebaran jalan dan penambahan moda transportasi. Dengan berkembangnya kawasan ini, dapat mengubah persepsi terhadap kawasan Sunda Kelapa sehingga layak untuk menjadi salah satu ikon wisata di Jakarta.

Ide cycle (Gambar 5) diterapkan pada sirkulasi dalam bangunan yang menerus agar pengunjung dapat menjelajahi seluruh ruangan dan kegiatan yang disajikan. Namun, disediakan juga akses langsung untuk pengguna khusus dengan sistem vertikal tangga dan elevator. Cycle atau siklus adalah putaran waktu yang di dalamnya terdapat rangkaian kejadian yang berulang-ulang secara bertahap dan teratur, daur. 
Gambar 5. Konsep Siklus dalam Sirkulasi Bangunan

Sumber: Olahan penulis, 2018.

\section{Fasade Bangunan}

Terdapat 2 (dua) jenis fasade yang berbeda digunakan, menggambarkan perbedaan perspektif manusia yang berdasarkan kreatifitas dan logika. Fasad kayu yang tidak beraturan menggambarkan kekreatifitas manusia dalam proyek ini yaitu mengolah sampah menjadi kerajinan tanggan yang mempunyai nilai seni dan ekonomi. Fasade dinding batu dengan void yang berirama dan teratur menggambarkan logika dalam proyek ini yaitu bagian perkantoran yang menjadi pengelola.

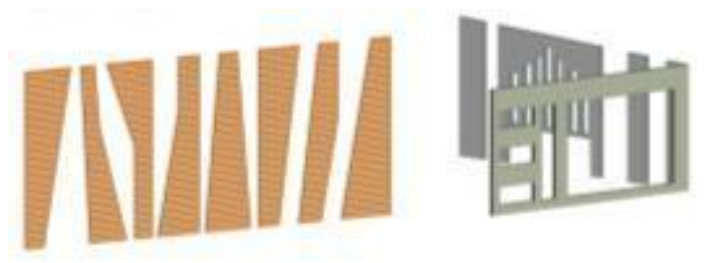

Gambar 6. Konsep Dseain Fasade Bangunan Sumber: Olahan penulis, 2018.

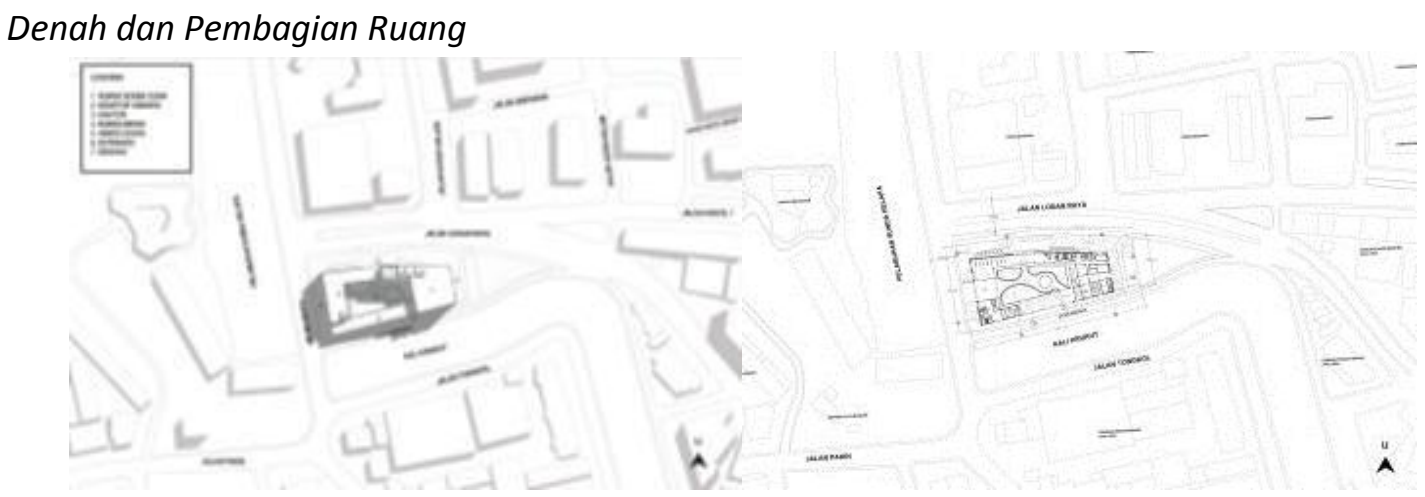

Gambar 7. Gambar Blok Plan (kanan) dan Gambar Site Plan (kiri) Sumber: Olahan penulis, 2018.

Perancangan pada proyek dilakukan dengan melakukan pembagian zonasi per lantai berdasarkan alur kegiatan dan hubungan antar ruang. Pada lantai dasar terdapat lobby utama dan area drop off yang langsung tersambung dengan area informasi, area informasi galeri dan ruang duduk. Entrance utama pejalan kaki memiliki akses paling dekat dengan linkage yang ada yaitu Museum Bahari untuk memudahkan perpindahan pengunjung dari bangunan satu ke bangunan lain. Terdapat juga side entrance khusus pejalan kaki. Seluruh entrance memiliki akses langsung terhadap inner courtyard yang berfungsi sebagai area duduk, penghijauan dan area seni instalasi ruang luar. Kegiatan yang ada pada lantai dasar merupakan hal-hal yang bersifat publik, sehingga terpisah dengan area privat. Sirkulasi pada bangunan menerus dengan menggunakan ramping agar pengunjung menjelajahi seluruh ruangan dan mengikuti seluruh kegiatan yang ada, namun ada akses langsung untuk para pengguna ruang-ruang khusus melalui lift maupun tangga yang dapat diakses dari entrance utama dan lobby utama. Selain area publik, terdapat juga area service yang merupakan area pengelolaan sampah yang memiliki akses tersendiri agar tidak menggangu pemandangan dan memudahkan aksesibilitas.

Lantai dua dapat dicapai melalui ramping yang dimanfaatkan sebagai ruangan penunjang berupa knowledge center, simulation center, dan installation art room sehingga perjalanan tidak akan membosankan. Menuju ke ruang pameran berisi benda-benda seni dua dimensi maupun tiga dimensi yang terbuat dari bahan dasar sampah. Terdapat juga ruang workshop 
tempat terciptanya karya kerajinan tangan yang memanfaatkan masyarakat sekitar untuk menambah perekonomian dengan memanfaatkan sampah di kawasan dan pengunjung pun bisa ikut berpartisipasi maupun belajar mengolah sampah menjadi barang layak pakai. Kerajinan tangan akan dijual di area retail yang mempunyai berbagai macam jenis benda.

Menuju ke lantai tiga melalui ramp yang berisi restoran-restoran lalu ke ruang pameran kedua yang juga berisi benda seni dari sampah. Lantai 3 didominasi oleh kantor pengelola yang mengatur galeri dan ruang lelang untuk memperjual belikan benda seni tersebut.

Menuju ke lantai 4 melalui ramp yang berupa roof top garden untuk memberikan perasaan yang berbeda-beda mulai dari lantai dasar menuju lantai dua yang bersifat indoor, lantai dua ke lantai tiga yang bersifat semi indoor dan lantai tiga ke lantai empat yang bersifat outdoor. Ruang serba guna digunakan untuk berbagai acara seminar dan juga disewakan untuk keperluan masyarakat sekitar.

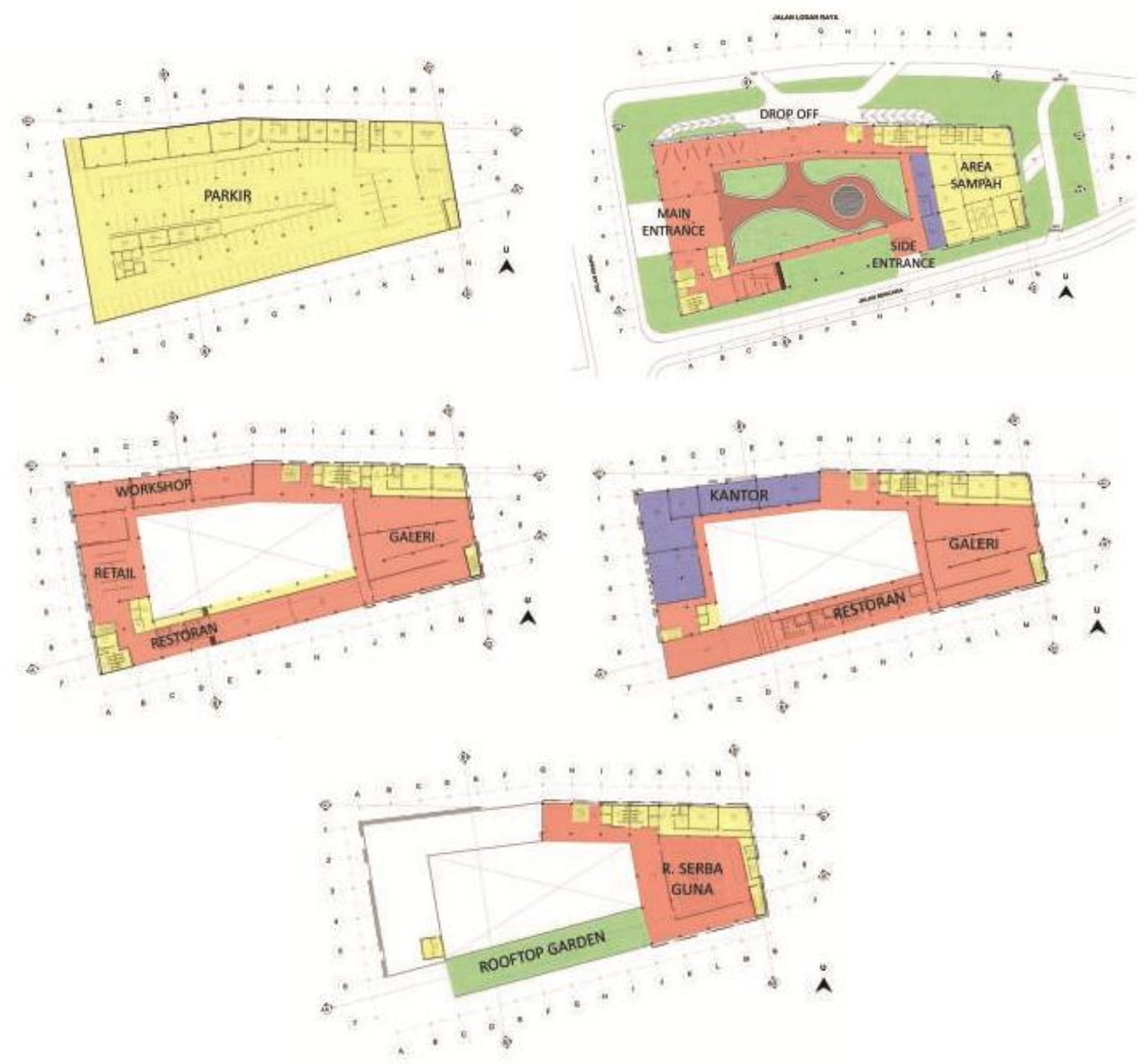

Gambar 8. Gambar Denah

Sumber: Olahan penulis, 2018.

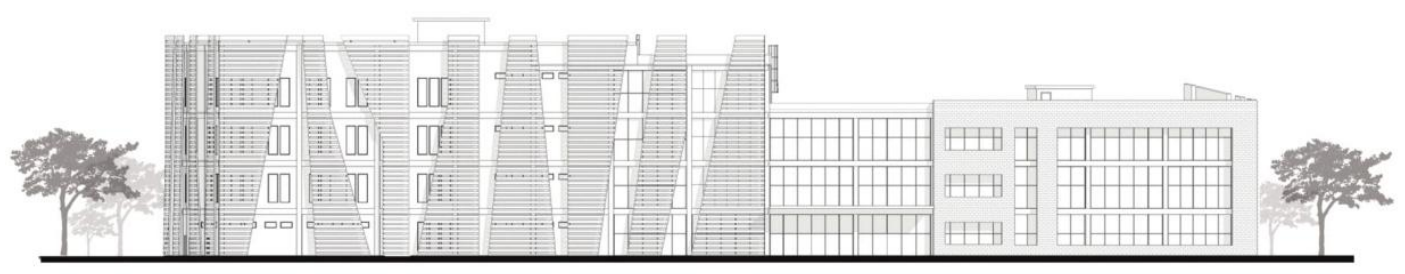

Gambar 9. Gambar Tampak Utara

Sumber: Olahan penulis, 2018. 


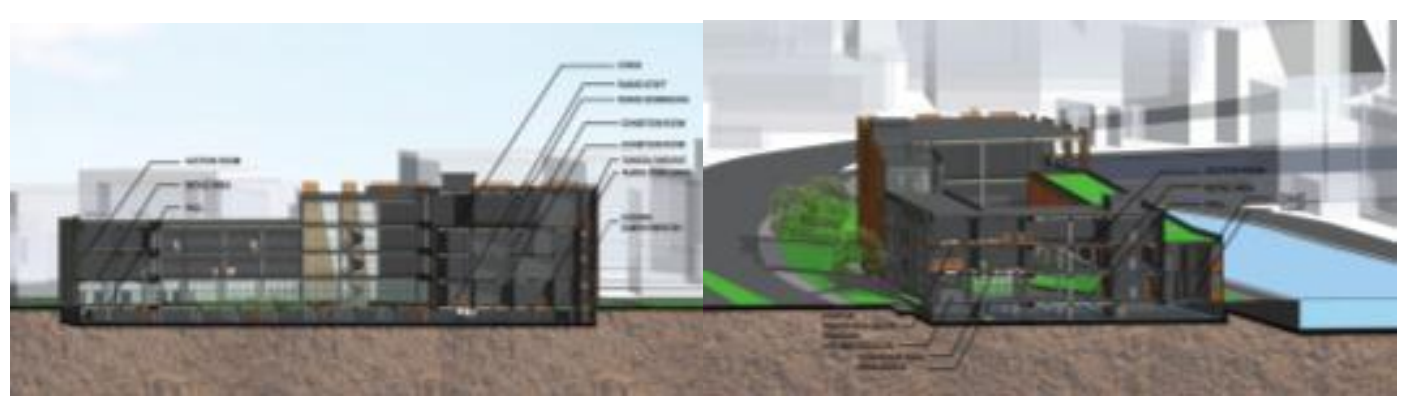

Gambar 10. Gambar Potongan Perspektif

Sumber: Olahan penulis, 2018.

\section{Struktur}

Struktur bangunan menyesuaikan dengan besar dan tinggi bangunan. Modul kolom yang digunakan mengikuti bentuk tapak (linear) karena bentuk dasar bangunan yang berupa kotak. Jarak antar kolom 8 meter $\times 8$ meter yang terbuat dari bahan beton bertulang. Balok induk dengan ukuran $60 \mathrm{~cm} \times 40 \mathrm{~cm}$ terbuat dari bahan beton bertulang. Balok anak berukuran $30 \mathrm{~cm}$ x $30 \mathrm{~cm}$. Ketebalan dinding core $20 \mathrm{~cm}$ yang digunakan pada basement dan tangga darurat.

\section{Mekanikal dan Elektrikal}

Ruang lingkup pekerjaan elektrikal dalam suatu bangunan adalah menyangkut persediaan sarana distribusi listrik dari panel utama ke panel sub distribusi hingga peralatan. Ruang panel utama berada di lantai basement dan menerus ke lantai teratas dengan adanya shaft, lalu dialirkan ke ruang-ruang lain dari ruang panel setiap lantainya. Ruang panel utama dapat mengontrol semua fungsi elektrikal dalam satu bangunan. Terdapat juga ruang trafo yang berfungsi untuk penyesuaian tegangan listrik. Sumber listrik bangunan berasal dari gardu listrik dan tenaga listrik cadangan dapat digunakan generator.

Sistem pengudaraan mayoritas menggunakan sistem pengudaraan buatan dengan VRV Sistem. Prinsip kerja VRV mengedepankan kenyamanan dan kemudahan. Keunggulan AC VRV adalah biaya perawatan terjangkau, mampu mengatur jadwal serta suhu, ramah lingkungan, sedikit outdoor untuk banyak indoor dan hemat listrik. AC VRV ini sangat cocok dengan fungsi bangunan komersil yang memiliki perbedaan jam kerja pada tiap ruangannya. Sistem penghawaan buatan yang digunakan pada bangunan ini berupa sistem VRV. Sistem VRV merupakan teknologi yang sudah dilengkapi dengan CPU dan kompresor inverter. VRV memiliki memiliki outdoor unit dan indoor unit, 1 outdoor unit dapat memiliki beberapa indoor unit. Outdoor unit pada bangunan ini di bagi menjadi 2 tempat untuk memenuhi kebutuhan keseluruhan ruangan.

Untuk sistem plumbing; adalah sistem pemipaan dalam bangunan yang memfasilitasi menyediakan air minum, penyaluran air buangan, penyediaan air panas, penyaluran air hujan, pengecahan kebakaran, penyediaan gas, dan penghawaan. Bangunan direncanakan memiliki GWT yang berfungsi sebagai penampung air di bawah yang akan dipompa ke reservoir atas dan disalurkan ke setiap lantai melalui shaft yang menerus. STP (Sewage Treatment Plant) berfungsi sebagai pengolahan air kotoran agar bisa digunakan kembali menjadi air siram tanaman, dll.

\section{KESIMPULAN DAN SARAN}

Proyek ini menjadi pemacu bangkitnya kawasan Sunda Kelapa menjadi wisata bahari di Jakarta dengan pembenahan lingkungan dalam aspek sampah. Pada proyek ini pun, menjadi tambahan objek wisata yang berintegrasi dengan bangunan wisata sekitarnya. Perkembangan Jakarta sebagai tuntutan modernitas tidak diimbangi dengan perkembangan pengelolaan sampah yang baik. Padahal sampah merupakan salah satu ancaman besar terhadap kerusakan 
lingkungan sehingga Jakarta harus segera berbenah untuk menghadapi permasalahan ini. Pembangunan Jakarta yang kian meluas menciptakan berbagai macam aktifitas yang mengharuskan adanya perkembangan dan pengembangan. Sikap ini merusak tatanan kota dan lingkungan jika tidak dilakukan penanganan dini. Kawasan Sunda Kelapa sebagai contoh dari pemasalahan lingkungan yang menganggu berkembangnya potensi wisata di kawasan tersebut. Proyek ini diharapkan dapat dikembangkan lebih lanjut sehingga bermanfaat bagi masyarakat dan pengembangan ilmu arsitektur di kemudian hari.

\section{UCAPAN TERIMA KASIH}

Pada kesempatan ini penulis mengucapkan terima kasih kepada para dosen pembimbing pendamping Tugas Akhir, Ketua Program Studi Sarjana Arsitektur Fakultas Teknik Universitas Tarumanagara, Ketua Jurusan Arsitektur dan Perencanaan Fakultas Teknik Universitas Tarumanagara, dan Pihak-pihak lain seperti orang tua, dan teman-teman yang telah memberikan dukungan moral baik secara materi, moral dan batin dalam penyusunan artikel Jurnal Stupa.

\section{REFERENSI}

Zahnd, M. (1999). Perancangan Kota secara Terpadu, Yogyakarta: Kanisius, pp 107-110.

Trancik, R. (1986). Finding Lost Space: Theories Of Urban Design, New York: Van Nostrand Reinhold, pp 106. 